\title{
Case Report \\ Euglycemic Diabetic Ketoacidosis in the ICU: 3 Case Reports and Review of Literature
}

\author{
Pablo Lucero $\mathbb{D D}^{1}$ and Sebastián Chapela $\mathbb{D i}^{1,2}$ \\ ${ }^{1}$ Hospital Británico de Buenos Aires, Intensive Care Services, Argentina \\ ${ }^{2}$ Universidad de Buenos Aires, Facultad de Medicina, Departamento de Bioquimica Humana, Argentina \\ Correspondence should be addressed to Pablo Lucero; pdlucero@hbritanico.com.ar
}

Received 9 July 2018; Accepted 16 September 2018; Published 1 October 2018

Academic Editor: Chiara Lazzeri

Copyright (C) 2018 Pablo Lucero and Sebastián Chapela. This is an open access article distributed under the Creative Commons Attribution License, which permits unrestricted use, distribution, and reproduction in any medium, provided the original work is properly cited.

\begin{abstract}
Diabetic ketoacidosis (DKA) is an acute complication of diabetes mellitus, both type I and type II, as well as other types with diabetes such gestacional diabetes mellitus. It is characterized by blood glucose levels greater than $250 \mathrm{mg} / \mathrm{dL}$ and metabolic acidosis $(\mathrm{pH}$ $<7.3$ and serum bicarbonate $<15 \mathrm{mEq} / \mathrm{dL}$ ) with an increased anion gap and the presence of ketone bodies in the blood or urine. Within this pathology, there is a subgroup of pathologies which are characterized by being present with no signs of hyperglycemia, posing a diagnostic challenge due to the absence of the main sign of the pathology and the diversity of their pathophysiology. In this article, we will present 3 clinical cases with 3 different forms of clinical presentation: a case of DKA in pregnancy, a case of DKA associated with the use of sodium-glucose cotransporter 2 (SGLT-2) inhibitors, and a third case related to sepsis, together with a narrative review of the literature on the topic.
\end{abstract}

\section{Introduction}

Diabetic ketoacidosis is an acute complication of diabetes. It is diagnosed through laboratory results showing metabolic acidosis with an increased gap and evidence of ketone bodies in the blood or urine. Most of the time, it is present with hyperglycemia. The clinical presentation of this pathology is diverse, going from abdominal pain to sensory deterioration and coma [1].

The pathophysiology of hyperglycemia in diabetic ketoacidosis has 3 cornerstones: an increase in gluconeogenesis, an increase in glycogenolysis and a decrease in peripheral glucose uptake due to a decrease in insulin action in the receptors or a decrease in insulin levels [1]. This prevents glucose from being transported inside the cells and being used as metabolic fuel. On the other hand, there is an increase in lipolysis and fatty acids start being used in the liver, where they are metabolized into ketone bodies, which can be absorbed by most cells [1].

Diabetic ketoacidosis is defined by the presence of blood glucose levels greater than $250 \mathrm{mg} / \mathrm{dL}$, being this the main finding, associated with metabolic acidosis $(\mathrm{pH}<7.3$ and serum bicarbonate $<15 \mathrm{mEq} / \mathrm{dL}$ ) with an increased anion gap and the presence of ketone bodies in the blood and/or urine [1]. There are different forms of presentation which differ from the usual presentation described in literature, such as the case of normoglycemic diabetic ketoacidosis. This pathology was first described by Munro in 1973 [2] but, in his work, he studied patients with blood glucose levels under $300 \mathrm{mg} / \mathrm{dL}$. Currently, the definition is in line with blood glucose levels under $250 \mathrm{mg} / \mathrm{dL}$ [1]. $6 \%$ of patients show blood glucose levels under $300 \mathrm{mg} / \mathrm{dL}$ and around $1 \%$ of patients show levels under $180 \mathrm{mg} / \mathrm{dL}$. The most common causes are insulin administration on the way to the hospital and fasting [1]. The diagnosis and treatment of this pathology require a deep pathophysiological knowledge, since it can be triggered by different etiologies. In this review, we will present 3 completely different cases of normoglycemic diabetic ketoacidosis.

\section{Clinical Case 1}

A 22-year-old woman with a history of diabetes mellitus (diagnosed at 7 years old) is treated with insulin glargine and 
TABLE 1: Patients' laboratory results upon admission to the ICU.

\begin{tabular}{|c|c|c|c|c|c|c|c|c|c|c|}
\hline & $\begin{array}{c}\mathrm{Na}+ \\
(\mathrm{mEq} / \mathrm{L})\end{array}$ & $\begin{array}{c}\mathrm{K}+ \\
(\mathrm{mEq} / \mathrm{L})\end{array}$ & $\begin{array}{c}\mathrm{Cl} \\
(\mathrm{mEq} / \mathrm{L})\end{array}$ & $\mathrm{pH}$ & $\begin{array}{c}\mathrm{HCO} 2 \\
(\mathrm{mEq} / \mathrm{L})\end{array}$ & $\begin{array}{c}\mathrm{BE} \\
(\mathrm{mEq} / \mathrm{L})\end{array}$ & GAP & $\Delta \mathrm{CL}$ & Ketonemia & $\begin{array}{c}\text { Blood } \\
\text { Glucose } \\
(\mathrm{mg} / \mathrm{dL})\end{array}$ \\
\hline CASE 1 & 137 & 4.9 & 102 & 7.25 & 10 & -14.9 & 23 & -0.75 & + & 153 \\
\hline CASE 2 & 142 & 3.9 & 108 & 7.13 & 2 & -23.7 & 32 & 1.5 & + & 165 \\
\hline CASE 3 & 140 & 4.8 & 109 & 7.28 & 7.3 & -16.8 & 23 & 4 & + & 132 \\
\hline
\end{tabular}

with good adherence to treatment, with hypothyroidism and 2 previous ICU admissions due to diabetic ketoacidosis in which blood glucose levels were greater than $300 \mathrm{mg} / \mathrm{dL}$.

The patient sought consultation due to vomiting and abdominal pain 12 hours after onset. Upon physical examination, the abdomen was distended with diffuse pain and no signs of peritoneal irritation. Laboratory results showed the following values: $\mathrm{pH}$ : 7.25; bicarbonate: $10 \mathrm{mEq} / \mathrm{dL}$; $\mathrm{BE}$ : -14.9; blood glucose: $153 \mathrm{mg} / \mathrm{dL}$ and positive ketonemia. Admission laboratory results are shown in Table 1. Upon diagnosis of normoglycemic diabetic ketoacidosis, in the context of menstrual cycle alterations and with the aim of studying the trigger, beta subunit of human chorionic gonadotropin levels was requested: 98.928 IU/L. A transvaginal ultrasound was performed and showed a gestational sac with an embryo inside. Reanimation was started with parenteral crystalloids administered at $250 \mathrm{~mL} / \mathrm{h}$ during $24 \mathrm{hrs}$. It was interspersed isotonic saline solutions and polyelectrolyte solutions. Total income is $7000 \mathrm{ml} / 24 \mathrm{hs}$. Urinary volume is $2750 \mathrm{ml} / 24 \mathrm{hs}$. Positive balance is $4250 \mathrm{ml} / 24 \mathrm{hs}$. Continuous insulin infusion was started, as described in literature (receiving a total of $100 \mathrm{IU}$ in $48 \mathrm{hrs}$ ). Progress was shown with improvement of the clinical condition and lab monitoring every 8 hours: $\mathrm{pH} 7.47$; bicarbonate of $22 \mathrm{mEq} / \mathrm{dL}$ with blood glucose levels in the normal range $(<200 \mathrm{mg} / \mathrm{dl})$. The usual insulin glargine dose was restored and the patient was discharged.

\section{Clinical Case 2}

A 50-year-old woman, former smoker, with a history of arterial hypertension, dyslipidemia, left side breast cancer which required chemotherapy, radiation therapy and surgery, hypothyroidism, and diabetes mellitus type II, is treated with $10 \mathrm{mg} /$ day of Dapagliflozin, $1000 \mathrm{mg}$ of Metformin every 12 hours, and NPH insulin at 40 and 60 IU. The patient sought consultation due to abdominal pain, diarrhea and fever. Upon admission, the patient was alert, tachypneic, and being with diffuse abdominal pain with no sign of peritoneal irritation. An abdominal ultrasound was requested and showed the gallbladder with multiple gallstones. The complete laboratory results are shown in Table 1 . In the context of leukocytosis, acute kidney failure, and severe metabolic acidosis, the patient was admitted to the ICU with a diagnosis of sepsis. Due to the presence of metabolic acidosis with a gap of 32, a ketonemia test was requested. The result was positive and the patient was diagnosed with euglycemic diabetic ketoacidosis.
After starting treatment with a continuous insulin infusion pump and the administration of water, the patient was discharged from the hospital after 5 days.

\section{Clinical Case 3}

A 74-year-old male patient with a history of arterial hypertension, noninsulin dependent diabetes mellitus medicated with oral hypoglycemic agents, ischemic cardiopathology with stent placement, nonoliguric chronic kidney failure, and cryptogenic liver cirrhosis required a liver transplant and subsequently suffered portal vein thrombosis requiring anticoagulation. The patient sought consultation after 3 days of passing liquid stools, together with emesis. He denied having fever spikes and, on that date, consulted the emergency ward of this institution, to which he was admitted feeling alert, with AT: 130/64, heart rate: 108 beats per minute, and SO2: $97 \%$ on room air. Upon physical examination, the patient was alert, tachypneic, and being with dry mucous membranes. Admission laboratory results are shown in Table 1. A ketonemia test was requested and the result was positive. The clinical presentation was interpreted as dehydration secondary to gastrointestinal losses and euglycemic diabetic ketoacidosis. Reanimation was started with crystalloids, a continuous insulin infusion pump, and the administration of intravenous bicarbonate. After $48 \mathrm{hrs}$, the patient presented DKA resolution criteria.

\section{Discussion}

Euglycemic diabetic ketoacidosis is a diagnostic challenge for treating physicians, since there is no hyperglycemia. On the other hand, there are many causes of metabolic acidosis in patients in the intensive care unit, although, when analyzing the gap, high gap metabolic acidosis is less frequent than hyperchloremic acidosis [14]. Therefore, knowing this pathology is key when treating patients with diabetes. Moreover, the triggers are varied and, in this study, we presented 3 cases with two different pathophysiological causes.

This pathology is triggered by multiple causes (Table 2). The following pathophysiological mechanisms are common to all causes: a decrease in insulin action or secretion with a decrease in total glucose uptake at a cellular level, an increase in the production of counterregulatory hormones, and a decrease in glucose production by the liver or an increase in the excretion of glucose in the urine $[11,12]$. 
TABLE 2: Causes of euglycemic diabetic ketoacidosis.

\begin{tabular}{l}
\hline Fasting \\
Insulin use prior to hospital admission \\
Pregnancy \\
Use of SGLT-2 \\
Cocaine abuse \\
Pancreatitis \\
Cirrhosis \\
Use of insulin pump \\
Sepsis
\end{tabular}

SGLT-2: type 2 sodium-glucose cotransporter.

The first case deals with a diabetic patient who is pregnant. The reason that normal pregnancy increases blood glucose levels is based on the progressive insulin resistance, which normally occurs. This resistance also explains the worsening of pregestational diabetes during pregnancy. The exogenous insulin loses its effect as the pregnancy progresses. These effects are attributable to the destruction of insulin by the kidney and the action of placental insulinases.

At the beginning of pregnancy, insulin maintains its activity, and its concentration increases due to the hyperplasia of the Beta cells of the pancreatic islets, induced by the high concentrations of placental steroids. As a result of these changes, fasting glycemia decreases. The main effect of insulin in the body is to allow the storage of nutritious substrates to meet energy needs. The provision of food is intermittent while the consumption of energy is constant from where the need for storage arises. The maternal organism stores energies in the form of glucose and fats. In addition, human chorionic gonadotropin causes vomiting, which causes fasting, dehydration, and metabolic acidosis [15].

As pregnancy progresses, the activity of the usual counterregulatory hormones such as human placental lactogen, which is synthesized by the trophoblast and released into the circulation, reduces maternal sensitivity to insulin, increasing postprandial blood glucose levels [10]. Progesterone reduces gastrointestinal motility, increasing glucose uptake [10]. In addition, there is a decrease in insulin sensitivity, particularly in the third trimester, caused by hormonal changes that occur during pregnancy like an increase in estrogen, progestogens, human placental lactogen, and secretion of TNF- $\alpha$ [15]. All these mechanisms induce hyperglycemia in pregnancy. On the other hand, the placenta and the fetus absorb large amounts of glucose, decreasing blood levels when fasting. This leads to an increase in the secretion of maternal fatty acids and their subsequent metabolization in ketone bodies [12].

During late pregnancy, the fetus dramatically increases its glucose-based metabolism and accentuates its anabolic process by growth. On the other hand, the maternal metabolism enters a catabolic process in order to send all the glucose to the fetus through the placenta, using fat as the primary fuel. In the diabetic patient, the decrease in insulin intake profoundly affects the general metabolism, particularly at the level of liver, muscle, and adipose tissue, which are insulin essential action points. The absence of this hormone causes distortion of homeostasis. Plasma levels of glucose, free fatty acids and ketones rise to extreme figures, plasma $\mathrm{pH}$ and bicarbonate fall dangerously and there is marked loss of fatty tissue and body mass. If insulin levels are not restored, this case can lead to death.

Finally, the respiratory alkalosis that occurs during pregnancy increases the urinary excretion of bicarbonate, reducing the ability to buffer $\mathrm{pH}$ changes caused by the increase in body ketone production [16]. This leads to euglycemic diabetic ketoacidosis in pregnancy.

The incidence rate of diabetic ketoacidosis in all pregnant women with diabetes varies between 0.5 and $3 \%$, being more common in patients with type I diabetes. However, there are more and more cases of patients with type II and gestational diabetes $[17,18]$. In a unicentric study in which 223,000 deliveries were analyzed, 14,532 (6.5\%) were complicated due to diabetes, just 33 patients presented 40 diabetic ketoacidosis episodes with average blood glucose levels of $380 \mathrm{mg} / \mathrm{dL}$ on admission, whereas only 3 cases presented euglycemic diabetic ketoacidosis [18]. The different cases of euglycemic diabetic ketoacidosis in pregnancy, their initial diagnosis, and clinical presentations are analyzed in Table 3. In contrast to most of the cases described in literature, our patient presented with DKA during the first trimester.

The harmful effects of ketoacidosis on the fetus are caused by ketone bodies and glucose passing the placental barrier, dehydration, which leads to decreased placental perfusion and electrolyte imbalance [18]. Fetal acidosis is caused by hyperglycemia, which leads to osmotic diuresis and fetal intravascular volume depletion. Fetal hyperinsulinemia increases oxygen uptake. A decrease in 2,3-DPG increases oxygen affinity for hemoglobin, reducing the amount of oxygen available to the fetus and generating hypoxia [17]. The electrolyte disturbance can not only generate maternal arrhythmias with a subsequent decrease in placental perfusion, but also generate fetal arrhythmias and risk of cardiorespiratory arrest [18]. Although there are no studies that show the long-term consequences for the fetuses born alive, neurodevelopmental alterations were observed. In contrast to other pregnancy complications, a hasty delivery with DKA would be harmful to the fetus. Therefore, it is recommended to stabilize the mother first [19]. Some studies state that fetal mortality in patients with DKA can reach 9\% [15] and perinatal mortality is between 9 and 35\% [17]. However, there are also authors who argue that ketoacidosis is not associated with a higher mortality rate during the first trimester, nor with a higher rate of malformations [20].

The mainstay of treatment does not differ from the treatment for hyperglycemic ketoacidosis, that is, hydration and insulin. The difference is that, in order to maintain blood glucose levels, the amount of glucose administered must be higher and, in the case of pregnant patients, care should be taken to maintain blood glucose levels suitable for fetal welfare. There is evidence in literature showing that a value of $250 \mathrm{mg} / \mathrm{dL}$ (Baha M. 2014) or values between 100 and 150 $\mathrm{mg} / \mathrm{dL}$ would accomplish this [20].

The second case is associated with the use of sodiumglucose cotransporter 2 (SGLT-2) inhibitors. The incidence 
TABLE 3: Cases of euglycemic DKA in pregnancy reported in literature.

\begin{tabular}{|c|c|c|c|c|c|c|c|}
\hline Author and Year & $\begin{array}{l}\text { Age of the } \\
\text { Patient }\end{array}$ & $\begin{array}{c}\text { Gestational } \\
\text { Week }\end{array}$ & $\begin{array}{l}\text { Obstetric } \\
\text { History }\end{array}$ & $\begin{array}{c}\text { History of } \\
\text { Diabetes }\end{array}$ & $\begin{array}{c}\text { Blood Glucose } \\
\text { upon Admission }\end{array}$ & $\begin{array}{c}\mathrm{pH} \text { upon } \\
\text { Admission }\end{array}$ & $\begin{array}{c}\text { Triggering } \\
\text { Factor }\end{array}$ \\
\hline Darhambulla, 2012 [3] & 30 years old & 33 & $\begin{array}{c}\text { Pregnancy: } 2 \\
\text { Borns:? }\end{array}$ & $\begin{array}{c}\text { Recently } \\
\text { diagnosed } \\
\text { gestational } \\
\text { diabetes }\end{array}$ & $95 \mathrm{mg} / \mathrm{dL}$ & 7.17 & $\begin{array}{l}\text { Urinary tract } \\
\text { infection }\end{array}$ \\
\hline Cardonell, 2016 [4] & 33 years old & 35 & $\begin{array}{c}\text { Pregnancy: } 3 \\
\text { Borns: } 2\end{array}$ & Diabetes type II & $134 \mathrm{mg} / \mathrm{dL}$ & 7.02 & $\begin{array}{c}\text { Unknown. } \\
\text { During delivery }\end{array}$ \\
\hline Chico, 2008 [5] & 29 years old & 24 & $\begin{array}{l}\text { Pregnancy: } 2 \\
\text { Borns: } 1\end{array}$ & Diabetes type I & $93 \mathrm{mg} / \mathrm{dL}$ & 7.22 & $\begin{array}{c}\text { Unknown. } \\
\text { During delivery }\end{array}$ \\
\hline Franke, 2001 [6] & 23 years old & 32 & Unknown & $\begin{array}{c}\text { Recently } \\
\text { diagnosed } \\
\text { gestational } \\
\text { diabetes } \\
\end{array}$ & $127 \mathrm{mg} / \mathrm{dL}$ & 7.2 & $\begin{array}{c}\text { Influenza A } \\
\text { infection }\end{array}$ \\
\hline Kamalakannan, 2003 [7] & 28 years old & 36 & $\begin{array}{l}\text { Pregnancy: } 5 \\
\text { Borns:? }\end{array}$ & Diabetes type I & $234 \mathrm{mg} / \mathrm{dL}$ & 7.1 & $\begin{array}{c}\text { Vomiting and } \\
\text { poor treatment } \\
\text { adherence }\end{array}$ \\
\hline Karpate, 2013 [8] & 25 years old & 37 & $\begin{array}{l}\text { Pregnancy: } 1 \\
\text { Borns: } 0\end{array}$ & None & $102 \mathrm{mg} / \mathrm{dL}$ & N/A & Fasting \\
\hline Napoli, 2011 [9] & 26 years old & 34 & $\begin{array}{c}\text { Pregnancy: } 3 \\
\text { Borns: } 2\end{array}$ & Diabetes type I & $211 \mathrm{mg} / \mathrm{dL}$ & 7.25 & $\begin{array}{c}\text { Altered food } \\
\text { intake }\end{array}$ \\
\hline Oliver, 2007 [10] & 29 years old & 28 & $\mathrm{~N} / \mathrm{A}$ & Diabetes type I & $205 \mathrm{mg} / \mathrm{dL}$ & 7.15 & $\begin{array}{l}\text { Bronchial } \\
\text { pneumonia }\end{array}$ \\
\hline Rivas, $2016[11,12]$ & 39 years old & 32 & $\begin{array}{c}\text { Pregnancy: } 2 \\
\text { Borns: } 1\end{array}$ & None & $225 \mathrm{mg} / \mathrm{dL}$ & 7.15 & Emesis \\
\hline Tarif, 2007 [13] & 37 years old & 35 & $\begin{array}{l}\text { Pregnancy: } 5 \\
\text { Borns: } 4\end{array}$ & $\begin{array}{c}\text { Gestational } \\
\text { diabetes }\end{array}$ & $78 \mathrm{mg} / \mathrm{dL}$ & 7.32 & $\begin{array}{c}\text { Emesis and } \\
\text { diarrhea }\end{array}$ \\
\hline
\end{tabular}

rate of diabetic ketoacidosis in patients treated with SGLT-2 inhibitors varies between 0.16 and 0.76 cases per 1000 patients per year $[21,22]$. In a review of literature, 46 cases of diabetic ketoacidosis associated with the use of SGLT-2 were found and, in $70 \%$ of the cases, the ketoacidosis was euglycemic [23]. The main mechanism of action is the inhibition of glucose uptake in proximal tubules, increasing glycosuria [24]. In addition, SGLT-2 inhibitors significantly increase plasma glucagon levels through a decrease in paracrine inhibition of insulin and possibly due to the inhibition of glucose transport into pancreatic $\alpha$ cells by SGLT-2 [22]. At the same time, they decrease 3-hydroxybutyrate and acetoacetate elimination at the kidney level [24-28]. Moreover, when blood glucose levels decrease, patients that are being treated with insulin decrease its administration. Therefore, counterregulatory hormone effects predominate, resulting in a lower inhibition of lipolysis and lipogenesis and, thereby, triggering euglycemic ketoacidosis [29-31]. Case reports include the 3 drugs of the gliflozin class: Dapagliflozin [24, 25, 29-35], Canagliflozin [26-28, 3133, 36, 37], and Empagliflozin [38-40].

The last case deals with a patient with diabetic ketoacidosis associated with dehydration. During fasting, when hepatic glycogen is consumed, there is no source of glucose release into the bloodstream; however, lipolysis and the generation of ketone bodies are increased [41]. Dehydration is also a factor that contributes to the development of euglycemia [42].

Luethi et al. [43] analyzed blood glucose levels, arterial blood gases, and ketonemia and ketonuria in 60 critically ill patients. $63 \%$ of the patients developed some degree of ketosis ( $\beta$-hydroxybutyric levels greater than $0.6 \mathrm{mmol} / \mathrm{L}$ ). In $12 \%$ of the patients, it was severe (greater than $3 \mathrm{mmol} / \mathrm{L}$ ), and $33 \%$ developed ketonuria (which was only severe in $2 \%$ of the patients). The prevalence of ketosis was the same in those who presented glucose peaks greater than $180 \mathrm{mg} / \mathrm{dL}$ and those who did not [1]. It is interesting to observe that, in this study [44], only 2 patients out of the 60 developed ketoacidosis based on the criteria set forth by the Joint British Diabetes Society [45] and none of them did, based on the ADA's criteria [11].

Finally, another possible cause of euglycemic ketoacidosis is the administration of insulin before being admitted to the hospital [42]. Other causes are pancreatic lesions developed during pancreatitis due to alcohol consumption, associated with the fasting required by this condition, which would explain the development of euglycemic ketoacidosis [42]. Furthermore, cocaine abuse causes an increase in the secretion of cortisol and noradrenaline by the adrenal gland, in addition to the anorexigenic effects of this drug, which lead to fasting [46].

\section{Conclusion}

Euglycemic diabetic ketoacidosis is a diagnostic challenge, not only due to the absence of its most important sign, which is hyperglycemia, but also due to its varied triggers. Knowing the different contexts in which it can occur will allow us 
to suspect euglycemic diabetic ketoacidosis and begin rapid and adequate treatment of the precipitating cause, as well as aggressive hydration, glucose homeostasis through insulin administration, and the adjustment of electrolyte imbalances. A delay results in serious complications both in the fetus (in the case of gestational diabetes) and in the patient, increasing in-hospital morbidity and mortality.

\section{Conflicts of Interest}

The authors declare that they have no conflicts of interest.

\section{References}

[1] A. E. Kitabchi, G. E. Umpierrez, J. M. Miles, and J. N. Fisher, "Hyperglycemic crises in adult patients with diabetes," Diabetes Care, vol. 32, no. 7, pp. 1335-1343, 2009.

[2] J. F. Munro, I. W. Campbell, A. C. McCuish, and L. J. Duncan, "Euglycaemic diabetic ketoacidosis," British Medical Journal, vol. 2, no. 5866, pp. 578-580, 1973.

[3] B. Franke, D. Carr, and M. H. Hatem, "A case of euglycaemic diabetic ketoacidosis in pregnancy," Diabetic Medicine, vol. 18, no. 10, pp. 858-859, 2001.

[4] D. Kamalakannan, V. Baskar, D. M. Barton, and T. A. M. Abdu, "Diabetic ketoacidosis in pregnancy," Postgraduate Medical Journal, vol. 79, no. 934, pp. 454-457, 2003.

[5] S. J. Karpate, H. Morsi, M. Shehmar, J. Dale, and C. Patel, "Euglycemic ketoacidosis in pregnancy and its management: case report and review of literature," European Journal of Obstetrics \& Gynecology and Reproductive Biology, vol. 171, no. 2, pp. 386387, 2013.

[6] A. Napoli, M. Framarino, A. Colatrella et al., "Eating disorders and diabetic ketoacidosis in a pregnant woman with type 1 diabetes: A case report," Eating and Weight Disorders, vol. 16, no. 2, pp. e146-e149, 2011.

[7] R. Oliver, P. Jagadeesan, R. J. Howard, and K. Nikookam, "Euglycaemic diabetic ketoacidosis in pregnancy: An unusual presentation," Journal of Obstetrics \& Gynaecology, vol. 27, no. 3, p. 308, 2007.

[8] M. Rivas M, P. Belmar Z, P. Durruty A, L. Sanhueza M, and G. López S, "Cetoacidosis diabética normoglicémica en el embarazo: Caso clínico," Revista Médica de Chile, vol. 144, no. 10, pp. 1360-1364, 2016.

[9] N. Tarif and W. Al Badr, "Euglycemic diabetic ketoacidosis in pregnancy," Saudi Journal of Kidney Disease and Transplantation, vol. 18, no. 4, pp. 590-593, 2007.

[10] B. M. Sibai and O. A. Viteri, "Diabetic ketoacidosis in pregnancy, Obstetrics \& Gynecology, vol. 123, no. 1, pp. 167-178, 2014.

[11] A. A. Abdin, M. Hamza, M. S. Khan, and A. Ahmed, "ase Report Euglycemic Diabetic Ketoacidosis in a Patient with Cocaine Intoxication," Case Reports Crit Care, vol. 2016, 2016.

[12] F. Le Neveu, B. Hywel, and J. N. Harvey, "Euglycaemic ketoacidosis in patients with and without diabetes," Practical Diabetes, vol. 30, no. 4, pp. 167-171, 2013.

[13] V. N. Baş, S. Uytun, and Y. A. Torun, "Diabetic euglycemic ketoacidosis in newly diagnosed type 1 diabetes mellitus during Ramadan fasting," Journal of Pediatric Endocrinology and Metabolism, vol. 28, no. 3-4, pp. 333-335, 2015.

[14] P. M. Gauthier and H. M. Szerlip, "Metabolic acidosis in the intensive care unit," Critical Care Clinics, vol. 18, no. 2, pp. 289$308,2002$.
[15] M. G. Dalfrà, S. Burlina, G. Sartore, and A. Lapolla, "Ketoacidosis in diabetic pregnancy," The Journal of Maternal-Fetal and Neonatal Medicine, vol. 29, no. 17, pp. 2889-2895, 2016.

[16] S. N. Bryant, C. L. Herrera, D. B. Nelson, and F. G. Cunningham, "Diabetic ketoacidosis complicating pregnancy," Journal of Neonatal-Perinatal Medicine, vol. 10, no. 1, pp. 17-23, 2017.

[17] M. d. Veciana, "Diabetes ketoacidosis in pregnancy," Seminars in Perinatology, vol. 37, no. 4, pp. 267-273, 2013.

[18] J. A. Parker and D. L. Conway, "Diabetic Ketoacidosis in Pregnancy," Obstetrics and Gynecology Clinics of North America, vol. 34, no. 3, pp. 533-543, 2007.

[19] M. A. Carroll and E. R. Yeomans, "Diabetic ketoacidosis in pregnancy," Critical Care Medicine, vol. 33, no. 10, pp. S347-S353, 2005.

[20] R. M. Goldenberg, L. D. Berard, A. Y. Cheng et al., "SGLT2 Inhibitor-associated Diabetic Ketoacidosis: Clinical Review and Recommendations for Prevention and Diagnosis," Clinical Therapeutics, vol. 38, no. 12, pp. 2654-2664.el, 2016.

[21] H. Qiu, A. Novikov, and V. Vallon, "Ketosis and diabetic ketoacidosis in response to SGLT2 inhibitors: Basic mechanisms and therapeutic perspectives," Diabetes/Metabolism Research and Reviews, vol. 33, no. 5, p. e2886, 2017.

[22] J. A. Levine, S. L. Karam, and G. Aleppo, "SGLT2-I in the Hospital Setting: Diabetic Ketoacidosis and Other Benefits and Concerns," Current Diabetes Reports, vol. 17, no. 7, 2017.

[23] J. Rosenstock and E. Ferrannini, "Euglycemic diabetic ketoacidosis: a predictable, detectable, and preventable safety concern with SGLT2 inhibitors," Diabetes Care, vol. 38, no. 9, pp. 16381642, 2015.

[24] J. Adachi, Y. Inaba, and C. Maki, "Euglycemic diabetic ketoacidosis with persistent diuresis treated with canagliflozin," Internal Medicine, vol. 56, no. 2, pp. 187-190, 2017.

[25] D. A. Kelmenson, K. Burr, Y. Azhar, P. Reynolds, C. A. Baker, and N. Rasouli, "Euglycemic Diabetic Ketoacidosis With Prolonged Glucosuria Associated With the Sodium-Glucose Cotransporter-2 Canagliflozin," Journal of Investigative Medicine High Impact Case Reports, vol. 5, no. 2, p. 232470961771273, 2017.

[26] M. Jazi and G. Porfiris, "Euglycemic diabetic ketoacidosis in type 2 diabetes treated with a sodium-glucose cotransporter-2 inhibitor," Canadian Family Physician, vol. 62, no. 9, pp. 722e517, 2016.

[27] S. Maraka, A. E. Kearns, N. E. N. Kittah, and D. T. O’Keeffe, "Recurrent euglycemic diabetic ketoacidosis after discontinuation of sodium-glucose cotransporter 2 inhibitor," Diabetes Research and Clinical Practice, vol. 118, pp. 77-78, 2016.

[28] S. Ullah, N. Khan, H. Zeb, and H. Tahir, "Metabolic ketoacidosis with normal blood glucose: A rare complication of sodium-glucose cotransporter 2 inhibitors," SAGE Open Medical Case Reports, vol. 4, p. 2050313X1667525, 2016.

[29] H. Storgaard, J. I. Bagger, F. K. Knop, T. Vilsbøll, and J. Rungby, "Diabetic Ketoacidosis in a Patient with Type 2 Diabetes After Initiation of Sodium-Glucose Cotransporter 2 Inhibitor Treatment," Basic \& Clinical Pharmacology \& Toxicology, vol. 118, no. 2, pp. 168-170, 2016.

[30] S. Pujara and A. Ioachimescu, "Prolonged Ketosis in a Patient With Euglycemic Diabetic Ketoacidosis Secondary to Dapagliflozin," Journal of Investigative Medicine High Impact Case Reports, vol. 5, no. 2, p. 232470961771004, 2017.

[31] F. Brown and T. McColl, "Euglycemic Diabetic Ketoacidosis Secondary to Dapagliflozin Use: A Case Report," The Journal of Emergency Medicine, vol. 54, no. 1, pp. 109-111, 2018. 
[32] M. Ahmed, M. J. McKenna, and R. K. Crowley, "Diabetic ketoacidosis in patients with type 2 diabetes recently commenced on sglt-2 inhibitors: An ongoing concerN," Endocrine practice : official journal of the American College of Endocrinology and the American Association of Clinical Endocrinologists, vol. 23, no. 4, pp. 506-508, 2017.

[33] S. Dizon, E. J. Keely, J. Malcolm, and A. Arnaout, "Insights Into the Recognition and Management of SGLT2-Inhibitor-Associated Ketoacidosis: It's Not Just Euglycemic Diabetic Ketoacidosis," Canadian Journal of Diabetes, vol. 41, no. 5, pp. 499-503, 2017.

[34] M. Kim, "Euglycemic diabetic ketoacidosis with SGLT2 inhibitors in lean type 2 diabetes," Integrative Obesity and Diabetes, vol. 2, no. 4, 2016.

[35] A. L. Peters, E. O. Buschur, J. B. Buse, P. Cohan, J. C. Diner, and I. B. Hirsch, "Euglycemic diabetic ketoacidosis: a potential complication of treatment with sodium-glucose cotransporter 2 inhibition," Diabetes Care, vol. 38, no. 9, pp. 1687-1693, 2015.

[36] J. S. Kum-Nji, A. R. Gosmanov, H. Steinberg, and S. DagogoJack, "Hyperglycemic, high anion-gap metabolic acidosis in patients receiving SGLT-2 inhibitors for diabetes management," Journal of Diabetes and its Complications, vol. 31, no. 3, pp. 611614, 2017.

[37] Alehegn Gelaye, Abdallah Haidar, Christina Kassab, Syed Kazmi, and Prabhat Sinha, "Severe Ketoacidosis Associated with Canagliflozin (Invokana): A Safety Concern," Case Reports in Critical Care, vol. 2016, Article ID 1656182, 3 pages, 2016.

[38] N. Candelario and J. Wykretowicz, "The DKA that wasn't: A case of euglycemic diabetic ketoacidosis due to empagliflozin," Oxford Medical Case Reports, vol. 2016, no. 7, pp. 144-146, 2016.

[39] P. D. Farjo, K. M. Kidd, and J. L. Reece, "A case of euglycemic diabetic ketoacidosis following long-term empagliflozin therapy," Diabetes Care, vol. 39, no. 10, pp. e165-e166, 2016.

[40] W. Ogawa and K. Sakaguchi, "Euglycemic diabetic ketoacidosis induced by SGLT2 inhibitors: Possible mechanism and contributing factors," Journal of Diabetes Investigation, vol. 7, no. 2, pp. 135-138, 2016.

[41] J. Prater and J. Chaiban, "Euglycemic diabetic ketoacidosis with acute pancreatitis in a patient not known to have diabetes," Endocrine Practice, vol. 1, no. 2, pp. e88-e91, 2015.

[42] N. Luethi, L. Cioccari, M. Crisman, R. Bellomo, G. M. Eastwood, and J. Mårtensson, "Prevalence of ketosis, ketonuria, and ketoacidosis during liberal glycemic control in critically ill patients with diabetes: an observational study," Critical Care, vol. 20, no. 1, 2016.

[43] M. W. Savage, K. K. Dhatariya, A. Kilvert et al., "Joint British Diabetes Societies guideline for the management of diabetic ketoacidosis," Diabetic Medicine, vol. 28, no. 5, pp. 508-515, 2011.

[44] S. Darbhamulla, N. Shah, and P. Bosio, "Euglycaemic ketoacidosis in a patient with gestational diabetes," European Journal of Obstetrics \& Gynecology and Reproductive Biology, vol. 163, no. 1, pp. 118-119, 2012.

[45] B. L. Cardonell, B. A. Marks, and M. H. Entrup, "Normoglycemic Diabetic Ketoacidosis in a Pregnant Patient with Type II Diabetes Mellitus Presenting for Emergent Cesarean Delivery," A \& A case reports, vol. 6, no. 8, pp. 228-229, 2016.

[46] M. Chico, S. N. Levine, and D. F. Lewis, "Normoglycemic diabetic ketoacidosis in pregnancy," Journal of Perinatology, vol. 28, no. 4, pp. 310-312, 2008. 


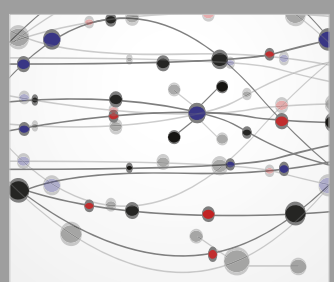

The Scientific World Journal
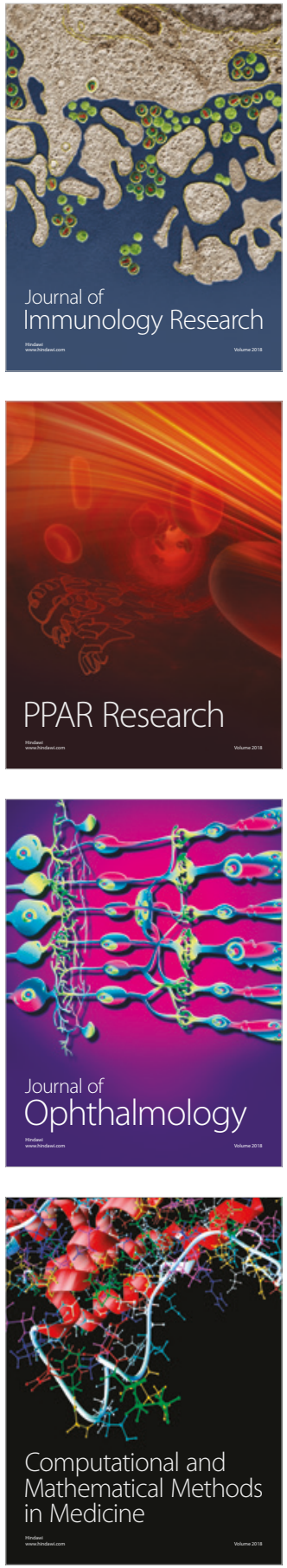

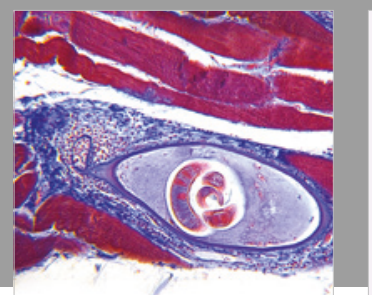

Gastroenterology Research and Practice

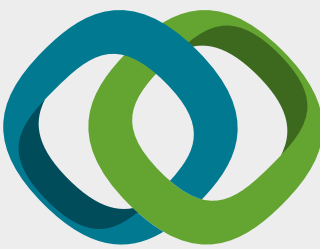

\section{Hindawi}

Submit your manuscripts at

www.hindawi.com
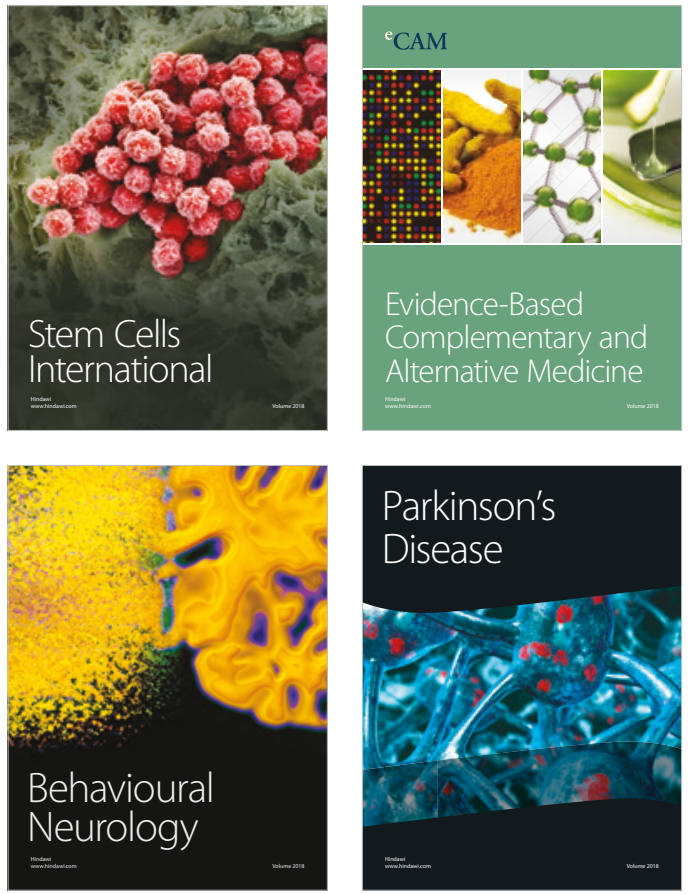

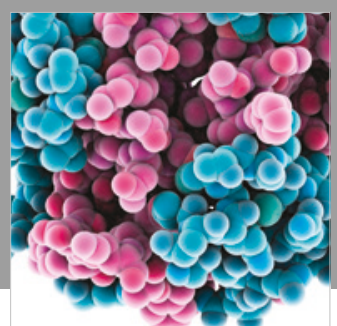

ournal of

Diabetes Research

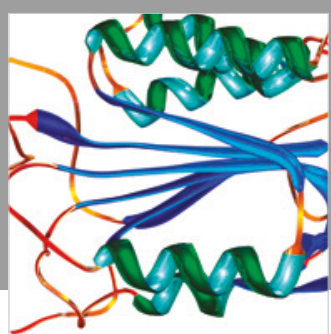

Disease Markers
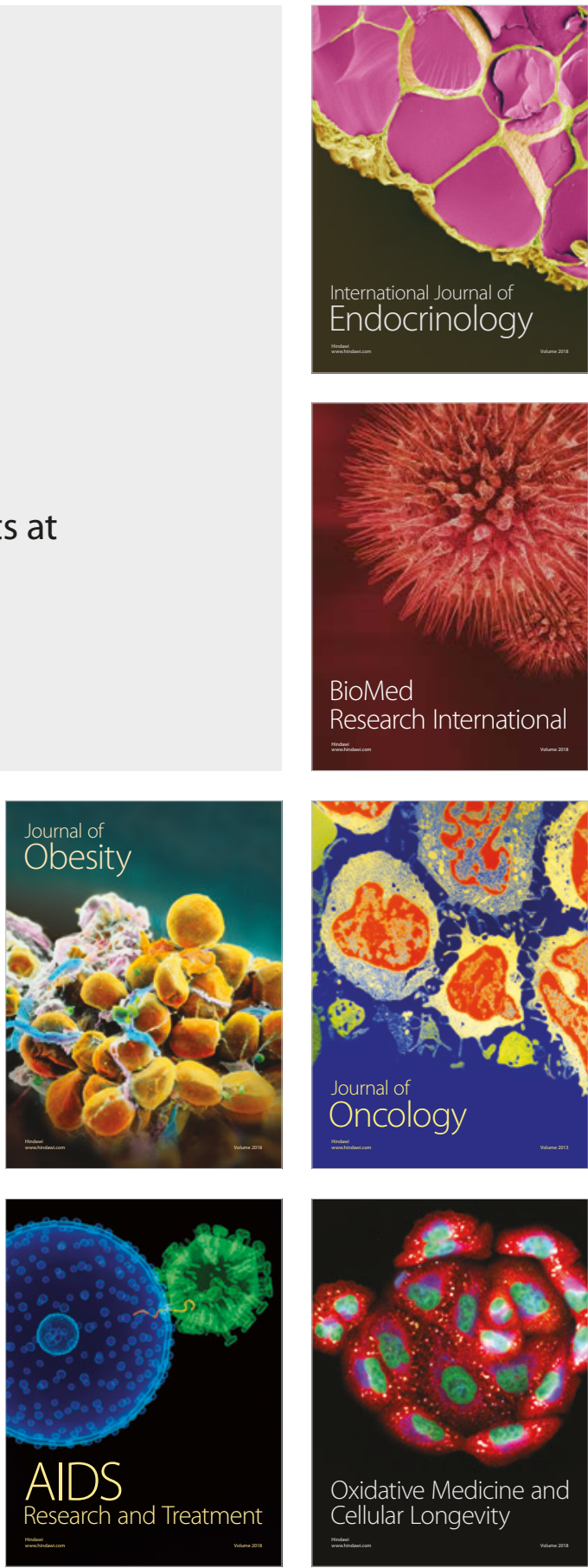